\title{
Interplay between Mediterranean Diet and Gut Microbiota in the Interface of Autoimmunity: An Overview
}

Christina Tsigalou ${ }^{1}$, Avgi Tsolou ${ }^{2}$, Theocharis Konstantinidis ${ }^{1}$,Efterpi Zafiriou ${ }^{3}$, Dardiotis Efthymios ${ }^{4}$, Alexandra Tsirogianni ${ }^{5}$, Dimitrios Bogdanos ${ }^{6}$

${ }^{1}$ Laboratory of Microbiology, Medical School, Democritus University of Thrace, University Hospital,68100-Dragana,Alexandroupolis, Greece

${ }^{2}$ Laboratory of Molecular Cell Biology, Cell Cycle and Proteomics,Department of Molecular Biology and Genetics,Democritus University of Thrace, 68100-Dragana,Alexandroupolis, Greece

${ }^{3}$ Department of Dermatology, Faculty of Medicine, School of Health Sciences, University of Thessaly, Larissa, Greece

${ }^{4}$ Department of Neurology, Faculty of Medicine, School of Health Sciences, University of Thessaly, Larissa, Greece

${ }^{5}$ Department of Immunology-Histocompatibility, Evangelismos General Hospital, Athens, Greece

${ }^{6}$ Department of Rheumatology and Clinical Immunology, Faculty of Medicine, School of Health Sciences, University of Thessaly, Larissa, Greece

\section{Correspondence to:}

Christina Tsigalou, MD, $\mathrm{PhD}$

Laboratory of Microbiology, Medical School,

Democritus University of Thrace,

University Hospital, 68100-Dragana,

Alexandroupolis,Greece

Tel: +302551352195

Fax:+302551352182

E-mail address: ctsigalo@med.duth.gr

Keywords: autoimmune disease; autoimmunity; dysbiosis; Mediterranean diet; microbiome 


\section{Abbreviations:}

anti-Citrullinated Protein Antibody, ACPA

Antigen-Presenting Cells , APCs

C-reactive protein, CRP

Disease-Modifying anti-Rheumatic Drug, DMARD

Expanded Disability Status Score, EDSS

Glucosamine (N-acetyl)-6-Sulfatase,/GNS

Mediterranean Diet, MedDiet

Multiple sclerosis, MS

Next Generation Sequencing, NGS

Neuromyelitis optica, NMO

Rheumatoid Arthritis, RA

Tumor Necrosis Factor, TNF

Short-Chain Fatty Acids, SCFA 


\begin{abstract}
The nutritional habits regulate the gut microbiota and may provoke and/or prevent autoimmune disease. Western diet is rich in sugars, meat and poly-unsaturated fatty acids, which lead to dysbiosis of intestinal microbiota, disruption of gut epithelial barrier and chronic mucosal inflammation. On the other hand, Mediterranean Diet (MedDiet) is rich in $\omega 3$ fatty acids, fruits and vegetables and has anti-inflammatory properties, which can restore gut eubiosis. The effect of MedDiet and its components in health and disease states have been thoroughly analyzed in several studies. Moreover, several studies have specifically investigated the association between MedDiet, microbiota and risk for autoimmune diseases. Furthermore, the MedDiet has been associated with lower risk of cardiovascular diseases, which plays a critical role in reducing mortality in patients suffering from autoimmune diseases with comorbidities. The aim of the present review is to specifically highlight current knowledge regarding possible interactions of MedDiet with the patterns of intestinal microbiota focusing on autoimmunity and a blueprint through dietary modulations for the prevention and management of diseases's activity and progression.
\end{abstract}




\section{Introduction}

It is widely accepted that the Mediterranean Sea offers an ideal temperate environment, with regards to temperature, humidity and sunlight to the surrounding countries and nations. Most of the inhabitants of the Mediterranean Sea basin have specific dietary trends, which scientists believe that support a healthy state of life. Since the early 1960 's, it has become apparent that Mediterranean people follow a habitual way of eating with slight differences, the so called "Mediterranean Diet" (MedDiet). But it was not until 1993, when the Harvard School of Public Health, Ordway's Preservation and Exchange Trust and the European Office of World Health Organization, together with Greek researchers introduced the MedDiet Pyramid, based mainly on the eating patterns of Crete island and Southern Italy[1,2]. MedDiet is plant-orientated with high intake of vegetables, cereals, nuts and fruits - meaning lots of fiber-, and smaller quantities of animal products preferentially seafood and fish.

Over the last 15 years, research has yielded a wealth of knowledge regarding human microbiome. The inconceivable diversity and abundance of all living organisms (microbes, fungi, viruses, parasites), which co-evolved with humans for thousands of years and inhabit the human body was revealed by next generation technologies. Observations in both experimental models and in humans struggle to define the precise relations and interactions between microbiota and health, as well as their correlation to different diseases. Symbionts and pathobionts are in a constant battle within gut microbiota contributing to a final state of symbiosis or dysbiosis. Different external and internal factors affect the composition of gut microbiome and diet appears to be one of the most important. Dietary habits have figurative results in intestinal microbiota and MedDiet seems to favor specific phyla while suppressing others[3]. 
It is now well-recognized that dietary changes largely affect microbial populations, which in turn may modulate innate and adaptive immunity[4]. Modern techniques, as Next Generation Sequencing (NGS) managed to provide evidence for different stages of dysbiosis related to various immune-mediated and autoimmune diseases. Still, but our knowledge is limited regarding the cause-effect model and the exact results and the consequences of these interrelations $[5,6]$.

In this review, we attempt to summarize the likely interactions of the adherence to the MedDiet with intestinal microbiota in the interface of autoimmunity and potential dietary modulations for the early prevention and proper management of autoimmune diseases.

\section{Special features of the Mediterranean Diet and links to disease prevention or improvement}

Countries bordering the Mediterranean Sea have incorporated in their traditional food habits for years a healthy style of cooking and eating. The key components of MedDiet emphasize firstly, on the consumption of fruits and vegetables, nuts and whole grains, accompanied by healthy fats, mainly olive oil, spices and herbs, and secondly, on the small quantities of red meat and larger portions of fish and poultry. Additionally, the moderate drinking of red wine and physical activity/exercise is of great importance. In 2010, UNESCO introduced the latest definition of MedDiet that was widened to incorporate "a set of skills, knowledge, practices and traditions ranging from the landscape to the table, including the crops, harvesting, fishing, conservation, processing, preparation and, particularly consumption of food"[7].

Large-scale projects demonstrated that the advantageous effects on the well-being of the participants seem to be attributed mainly to healthy mono-unsaturated fatty acids in 
olive oil and flavonoids in red wine, nuts, spices etc [8-11]. These effects are accomplished through the anti-inflammatory and anti-oxidative actions of these components, leading to the decrease of inflammation and oxidative stress [8].

Research conducted over the last two decades has consistently shown that adherence to MedDiet is beneficial for prevention or amelioration of numerous inflammatory diseases. The lion's share of the studies underlines the significant role of the Mediterranean dietary pattern in preventing cardiovascular diseases [9], type II Diabetes [10], obesity and metabolic syndrome [11,12]. Moreover, increased interest in the diet's results on human morbidities underscores the effect of prolonged survival of the Elderly [13], better sleep and academic performance in teens [14], increased vitamin D levels, improvement of neck bone mineral density in adults who already had osteoporosis [15], longer length of telomeres in women[16], decreased depression in the Elderly [17], lower risk of fatty liver [18], lower risk of aggressive prostate cancer [19], prevention of colon cancer [20], reduced incidence of gestational diabetes and premature births [21], longevity [22], and improvement of arthritis symptoms [7]. Research claims that the key point of the MedDiet's benefits is the combinatorial consumption of several beneficial foods instead of following a stringent eating pattern. The advantage of single foods' or nutrients' protective action in the diet seems weaker against diseases, in comparison to adopting the entire plan [23].

\section{Effects of diet on gut microbial communities}

According to Hippocrates, the father of modern medicine, 'all diseases begin in the gut'. Centuries later, numerous studies, complicated reflections and ambitious projects elucidated the truth of this wisdom. Culture-independent techniques, as NGS in collaboration with biostatistics managed to complete the characterization of our body 
inhabitants from different body sites and concluded that the gastrointestinal tract (especially the gut) is, by far, the most populated site of the human body [24]. The genome of these gut microorganisms forms the gut microbiome, a very abundant and diverse ecosystem with complicated interactions among them as well as with the host, by affecting different aspects and maintaining human health throughout life. Largescale studies have dictated that different eating patterns promote a variety of gut microbiota composition and diversity and highlight diet as one of the most significant influencing factors $[3,6,25,26]$.

Different eating habits, alterations in dietary components -such as fats, proteins and carbohydrates-, food complements as probiotics and prebiotics, even salt composition, can all modulate the gut microbiota [27]. However, such changes can exert an effect not just at microbial species level but also at phyla differences[28]. Diets rich in carbohydrates or fats alter the numbers of various microbial species, increasing some and decreasing others, and as a whole they may reduce the microbiota diversity [2933]. However, addition of prebiotics may restore population alterations caused by highfat diet in obese mice [34]. Moreover, the gut microbiota of mice fed with increased amount of protein also showed significant increase or decrease of particular microbial genera and these alterations were dose-dependent [35]. In humans, gut microbiota varies at the species level, depending on fat and fiber or carbohydrate consumption, between omnivores and vegetarians, or even among vegetarian subgroups [3]. In general, eating habits have an effect on gut microbiota diversity, with meat consumption -in addition to fibers- allowing increased bacterial species diversity. This diversity lies on higher taxonomy levels, as phylum, family and genus, rather than at the species level. Alterations in single dietary components, such as gluten, may also change composition and function of the gut microbiome and host physiology of healthy 
individuals [36]. Effects of diet on gut microbiota are demonstrated by numerous studies, comparing different food habits, dependent on the geographical and socioeconomical differences seen in different areas [37-39]. Interestingly, a large-cohort study on US immigration from nonwestern countries showed a relatively fast (within 9 months of immigration) and long-term loss of gut microbiome diversity, loss of bacterial enzymes related to plant fiber degradation, displacement of native strains and functions and, as a result, predisposition of individuals to obesity and metabolic diseases. These profound perturbations in gut microbiome can be partially explained by dietary variations [40].

\section{Gut microbiome's link to autoimmunity}

It seems that apart from the identification of all taxa of microbes, the ultimate challenge is to define the benefits and drawbacks of the 'healthy gut'. The human microbiota, and the gut in particular, has been deemed an "essential organ", containing approximately 1000 different microbial species and counting for over 150 times more genes than those of the whole human genome[41,42]. The vital (essential/fundamental) role of human microbiota in health and disease includes a variety of mechanisms. The microbiota assists energy extraction from food, supplies unique enzymes and biochemical pathways to the human body, and acts as a physical barrier against foreign pathogens through antimicrobial substances or regional competition [43-45]. Last but not least, the gut microbiota is indispensable for the normal development of both the intestinal mucosa and the host humoral and cellular immune system, as signals and metabolites from the microorganisms are sensed by cells of the innate immune system and are recognized as physiological responses [46-48]. The term "autoimmunity" refers to activation of adaptive immune responses, with the involvement of $\mathrm{T}$ and $\mathrm{B}$ lymphocytes against self-antigens, i.e. against its own healthy cells and tissues. The actual causes of 
autoimmunity are not fully understood, but various environmental factors, including diet, lifestyle and infections, along with the genetic background of the host, seem to play a role $[49,50]$. The principle of initiating the adaptive immune responses lies in the innate-adaptive immune system connection. It is the innate immune system that can discriminate between self and non-self-antigens, whereas the adaptive immune system recognizes either native antigens or peptides connected to major histocompatibility complex molecules [51]. As a result, it is the adaptive immune system that responds to invasion of the host by a microbial pathogen or parasite. Studies in both humans and animal models designate the involvement of commensal microbiota in autoimmunity. Effects of the microbiota on autoimmune diseases that require the innate-adaptive immune system connection may vary from being neutral to being requisite for the induction of autoimmunity. The loss of immune tolerance to self-antigens can be a result of microbial composition alterations, and, thus, the human microbiota can be a key participant in the development and perpetuation of autoreactive immune responses which lead to self-tissue destruction and overt autoimmune disease $[52,53]$. There are several reasons for loss of immune tolerance and induction of autoimmunity by microorganisms, including molecular mimicry, bystander activation, and viral persistence with or without epitope spreading [54-58].

Epitope spreading refers to autoimmune responses to self-epitopes, when, at an inflammatory response self-antigen are released. These self-antigens can be a result of slightly changed antigens, even at an amino acid residue. As a result, the immune reaction will affect both the "wild" protein or the altered one[59].

In molecular mimicry, a shared immunologic epitope between a microbe and the host is the prerequisite for the initiation of cross-reactive immune responses. One of the finest examples of molecular mimicry as a mechanism responsible for the development 
of autoimmune disease is that in individuals with rheumatic fever after infections with group A beta-hemolytic streptococci. Analysis of infected hosts' sera demonstrated the presence of antibodies reactive with heart, joints, brain, and skin. Moreover, patients' antibodies are found to cross-react with streptococcal antigens, like the group A carbohydrate antigen, the $\mathrm{M}$ protein (a streptococcus- related virulence factor) and to cross-react with myosin. Cross-reactive peptides from $\mathrm{M}$ protein and cardiac myosin may provoke the onset of autoimmune disease in mice with rheumatic heart disease [60]. The mechanism of molecular mimicry can also operate at the T-cell level involving antigenic epitopes of human and foreign origin which serve as targets of CD4 and CD8 T-cell responses. Previous studies of our group has meticulously addressed the role of molecular mimicry in the induction of autoimmune diseases, primarily affecting the liver and the gastrointestinal tract [61-79].

Bystander activation/killing is another mechanism resulting in autoimmune diseases. Viral infections can activate Antigen-Presenting Cells (APCs) which, in turn, activate primed autoreactive T cells for the onset of autoimmune disease. Furthermore, initiation of bystander activation can be a result of virus-specific $\mathrm{T}$ cells. Bystander effect may lead to killing of the uninfected neighboring cells, that increases the immunopathology at the infected area [80]. Finally, persistent viral infections may cause immunopathology, as a result of the continuous presence of viral antigens challenging the immune system [80](Figure 1). 


\section{Adherence in MedDiet and its effects on microbiome related to autoimmune diseases: the case of rheumatoid arthritis}

The Mediterranean diet is rich in fiber, antioxidants and vitamins and encompasses antiinflammatory properties [81]. Various data have demonstrated that consumption of cereals, fruits and vegetables, nuts and legumes, omega-3 polyunsaturated fatty acids in olive oil and moderate consumption of red wine flavonoids leads to the reduction of pro-inflammatory cytokines, the increase of anti-inflammatory cytokines and the decrease of oxidative stress [82,83]. It has been shown, that adherence to a Mediterranean pattern diet leads to the reduction of CRP and TNF- $\alpha$ levels $[84,85]$.

Several studies investigated the role of MedDiet in Rheumatoid Arthritis (RA), a common autoimmune rheumatic disease. Skoldstam et al. reported data suggesting that the adoption of a MedDiet model reduced the inflammatory activity of the disease, increased functionality and improved the quality of life of patients with RA[86]. Another study claims that adherence to MedDiet is associated with decreased disease activity, better physical activity, as well as increased viability in RA individuals [86]. Subsequent studies have produced inconsistent results[86-93]. A recent systemic review analyzing the data so far provided from prospective human studies, concluded that MedDiet has beneficial effects in reducing pain and increasing physical function in people with RA but underline that so far there is unsatisfactory evidence to support widespread recommendation of MedDiet for the prevention and management of RA [7].

Data from studies on short term MedDiet, as well as fasting, found no effect of these diets on the microbiologically assessed intestinal flora of RA or fibromyalgia patients[94]. Recent studies have underlined the long term adherence (more than 3 
months) to MedDiet is needed to produce significant diversity in the gut microbiome of overweight omnivores [95]. The CARDIVEG study reported that MedDiet significantly alters the abundance of Lachnoclostridium, Enterorhabdus and Parabacteroides, while vegetarian diet significantly disturbs the abundance of Streptococcus, Anaerostipes, Clostridium sensustricto, and Odoribacter [95].

Such studies on gut microbiome changes in patients with RA adherent to MedDiet have not been performed so far, but several data from research conducted on the gut microbiome and its relation to RA may be relevant. Several studies have assessed changes of the intestinal microflora in relation to MedDiet in patients with RA. An early study suggested that changes of intestinal Short-Chain Fatty Acids (SCFA) from the intestinal microflora are not necessarily correlated with clinical improvements and disease activity in RA[96].

An association between MD and increased SCFAs production is well known[97].Rich fiber foods such as fruit, vegetables, and legumes which are repeatedly consumed by those adherent to MedDiet are degraded by Firmicutes and Bacteroidetes bacteria, leading to the production of high levels of feacal SCFA[98,99], which is beneficial for the intestinal barrier integrity; for example butyrate, the most extensively investigated functional SCFA produced during the fermentation of dietary fiber by the anaerobic intestinal microbiota, increases the expression of tight junction proteins and prevents from deleterious intestinal permeability and bacterial translocation, which have a blocking impact on the initiation of pro-inflammatory responses[100,101,98]. To relevance in collagen-induced arthritis, an animal model of RA, butyrate is able to suppress RA features and this is achieved via a butyrate-mediated increase of IL-10 producing Tregs and a decrease of Th17[102].However, not all Mediterranean type of diets increase SCFAs, and butyrate in particular at the same extent, and this may have 
an impact in their ability to suppress anti-inflammatory immune responses or to influence intestinal microbiota-related influence of the immune system. Modified Mediterranean type enriched for SCFA production are increasingly popular but their effect in RA has not been assessed. Omnivores who consume a MedDiet-pattern diet rich in fruit, legumes and vegetablesnot only have increased SCFAs [98] but also decreased trimethylamine $\mathrm{N}$-oxide (TMAO), a microbial metabolite the precursors of which are carnitine and choline which are primarily found in foods of animal origin [98,103]. Several microbial genera, like L-Ruminococcus, have been linked to the intake of animal proteins such as a diet plenty in red meat consumption and increased TMAO levels. This is very interesting, in view of recent data demonstrating a twofold to threefold increased abundance of Ruminococcus gnavusin patients with spondylarthritis and to a lesser extent in RA patients compared to healthy controls [104].

However, the most notable association over the last few years is that linking P.copri the TMAO-producing anaerobic, Gram-negative Bacteriodetes, with the development of RA, an association thoroughly reviewed elsewhere [105,106].Prevotella spp are abundant in the periodontium, the intestine, and the respiratory system and its enriched presence is considered a risk factor for RA and features associated with RA, such as cardiovascular risk-events [105,107-110]. Furthermore, it may alter the metabolism of the microbiota to reduce the effectiveness of the common disease-modifying antirheumatic drug (DMARD) methotrexate [111]. The question arises as to whether adherence to MedDiet alone or in combination with other diet supplementation can alter gut dysbiosis to a state that Prevotella spp. are not dominant $[61,112,113]$. This event would stop the vicious circle of immunological events that take place, Prevotella being in the center of it and could prevent from RA. 
A recent elegant study has shown that the microbiota of individuals in pre-clinical RA stages (early RA) had significantly altered faecal microbiota composition compared with their first-degree relatives (FDRs) [108].These pre-clinical RA, who had either developed anticitrullinated peptide antibodies or rheumatoid factor positivity and/or symptomatology and features associated with possible RA in 'pre-clinic stages' had faeces significantly enriched in of the bacterial family Prevotellaceae, particularly Prevotella spp. compared to their FDRs [108].

These data clearly demonstrate that Prevotella spp. enrichment in early RA and very early RA may indeed be a characteristic feature of these subclinical phenotype raising the expectation that Prevotella spp are pathogenically relevant to the development of the disease, from early stages, rather than consequence of established disease state.

We recently reviewed the existent literature tackling this topic and thoroughly discussed mechanistic scenarios, which could implicate Prevotella species in the establishment of RA [114]. We underlined the decisive role of Prevotella species in the potential induction of either ACPA-positive or ACPA-negative RA. This contrasts that of the well-known association of $P$. gingivalis and ACPA-positive RA and the inability of this oral commensal to explain the induction of ACPA-negative RA. Though several components of the Prevotella-host interactions are still puzzling and improperly explored, some of the features linking P. corpi, as well as oral Prevotella species, to RA are striking. One of the most fascinating has recently been obtained by Pianta et al [115]. These authors using liquid chromatography-tandem mass spectrometry identified two novel RA autoantigens, targeted by half of the ACPA-pos and ACPAnegative patients with RA. The two autoantigens were the N-acetyloglucosamine-6sulfatase (GNS) and filamin A (FLNA). Of interest, both GNS and FLNA were expressed in synovia, a finding that supports the notion that they could be relevant to 
immune-mediated tissue destruction. The former also appeared to be citrullinated, which makes it likely target of ACPA antibodies. Data indicating that antibody concentrations of these autoantibodies are correlated further supports the likely association of anti-GNS antibodies with ACPA [115].These autoantigens were recognized by more than half of the RA patients, and were also present in ACPAnegative RA. Of immunological relevance, Pianta et al found that the epitopic regions of GNS and FLNA not only are highly homologous to Prevotella corpi but are also targeted by B and T-cells responses, also cross-recognizing the Prevotella homologues. Thus, there is evidence that a molecular mimicry mechanism is in operation, which could account for the induction of those autoantibodies [115].Of relevance, molecular mimicry involving an oral Prevotella sp. and collagen I, have been previously reported and has been considered a likely trigger for chronic periodontitis and possibly inflammatory [116].

The GNS peptidyl sequence was highly homologous to a sequence from sulfatase proteins of the Prevotella sp. and Parabacteroides sp. Finding marked homologies between human and microbial highly conserved proteins is extremely common and the homology reported by Pianta et al belongs to this category. In a similar vein, homologies between human and microbial heat shock proteins and human and microbial 2-oxo-acid dehydrogenase complexes have been identified and suggested as triggers of various organ and non-organ specific immune-mediated and autoimmune diseases. Because they are extremely common, several investigators, including authorities in the field, suggested that molecular mimicry involving such homologues must not be regarded as a perpetuator of autoimmunity.

We carefully examined the reported similarities between human GNS and Prevotella. Pianta et al reported that the same human GNS sequence had also marked amino acid 
similarity with the gut commensal Parabacteroides sp. Using a BLAST program, we looked for additional similarities that could be potentially homologous to the human GNS epitope. We found several microbial mimics that have similarities with the core epitopic region of the human GNS epitope. For example, the pentameric -FFMMI- 224228 aa of human GNS is contained in the transmembrane protein of Streptococcus gordonii (aa 43-47), transcriptional regulator of Lactobacillus casei (aa 464-468), cetylCoA carboxylase, carboxyl transferase subunit beta of Clostridium cellulolyticum H10 (aa 133-137), hypothetical protein of Vibrio phage KVP40 (aa 23-27) and several other foreign proteins, suggesting that many other triggering factors may really exacerbate GNS-specific autoreactivity in RA by molecular mimicry.

Thus, Pianta's homologoues cannot be disregarded as the relevant mimics are targets of cross-reactive responses and the humoral responses against the microbial peptides are correlated with disease-specific autoantibodies i.e ACPAs.

We went a step further and postulated that gut dysbiosis leads to immunologic alterations, which are pivotal for the loss of immunological tolerance to RA-specific autoantigens. We considered that this is achieved in a stepwise manner and that several immunological mechanisms are involved, molecular mimicry being just one of those. Firstly, we have an external parameter, which leads to changes in the gut microbiome (as well as changes on the microbiome of the oral cavity) and an establishment of gut dysbiosis. This parameter or combination of parameters could be drugs, infections, changes of diet habits from Mediterranean diet to western diet etc). Gut dysbiosis in turn leads to the establishment of an immunological environment, which alter the composition of regulatory $\mathrm{T}$ and $\mathrm{B}$ cells and diminishes their capacity to suppress autoreactive immune responses and augments pro-inflammatory Th17 responses. Enrichment of specific species, such as that of Prevotella has also other consequences, 
most notably the activation of the immune system against a gut microbe and the initiation of anti-Prevotella responses, which by mechanisms of molecular mimicry and others, in concert with other mechanisms can lead to the induction of autoreactive responses. This initiation can lead to the development of autoimmune disease only in susceptible individuals [117].

Of indirect relevance to the topic we discuss, amongst the American indigenous populations, the Canadian Inuit population has the lowest age-adjusted prevalence of rheumatoid arthritis (at $0.65 \%$, with an incidence of 48.2 per 100,000 per year) [118]. This is of interest because a microbiome study has found that Prevotella spp., were enriched among the Inuit consuming a Western diet. However, the gut microbiomes of Inuit consuming a traditional high-fiber diet [119] had significantly less genetic diversity within the Prevotella genus, compared to the Inuit consuming a Western diet further, indicating that a low-fiber diet might not only select against Prevotella but also decrease its diversity, a factor which could be relevant to the induction of autoreactive responses implicating Prevotella in inflammatory arthritis.

A very recent study has shown that berberine modulates gut microflora and exerts an anti-inflammatory effect on collagen-induced arthritis [120]. This is achieved because the abundance of Prevotella is diminished and the abundance of butyrate-producing bacteria in CIA rats is increased [120].

However, a recent study investigating changes on gut microbiota associated to MedDiet found a higher presence of Bacteroidetes and a lower Firmicutes-Bacteroidetes ratio, who had a higher MedDiet score but failed to report significant differences in levels of Bacteroides and Prevotella, genus included in Bacteroidetes phyla [121]. Again, it is not clear whether long-term adherence to MedDiet may indeed exert an influence on 
the levels of Prevotella, which could in turn utilize beneficial effects in preventing from RA or ameliorating disease's clinical features. A recent study provided an integrative analysis of distal gut microbiota composition and functions and intestinal metabolites in Egyptian teenagers consuming MedDiet related products and compared them with a cohort of USA teenagers consuming a Western type of diet enriched in animal proteins, fats and processed carbohydrates [122]. The Prevotella enterotype predominated in gut microbial communities of the Egyptian teenagers while the Bacteroides enterotype dominated the USA cohort. As it was expected the intestinal environment of Egyptian teenagers was characterized by higher levels of SCFA, an increased prevalence of microbial polysaccharide degradation-encoding genes, and a higher proportion of several polysaccharide-degrading genera while the gut environment of the American children was enriched in proteolytic microbes and end products of protein and fat metabolism [122].

Multiple sclerosis (MS) and Neuromyelitis optica (NMO) is an autoimmune disease of the CNS, with some overlapping symptoms. A few studies have shown that both genetic and environmental factors may affect the etiology of the MS, including dietary habits. Moreover, the onset of the disease post microbial infections via molecular mimicry and bystander activation mechanisms is also a scenario $[123,124]$. The multiple role of gut microbiome on MS pathogenesis has been shown in a reciprocal way; germ free or gnotobiotic mice demonstrated considerably reduced susceptibility to experimental autoimmune encephalomyelitis (EAE), a MS model, while CNS disease may affect gut homeostasis. The gut-brain connection is largely supported by evidence on individuals with MS [125,126]. Th17 cells are normally required for host defense against invaders, but they may have vicious effects in terms of autoimmunity, also suggested by their increased numbers in MS. The role of gut microbiota in Th17 cells and their IL-17 
product, and their increased numbers of the latter ones in MS have been reviewed in detail $[127,128]$. On top of that, the main role of Tregs is the suppression of autoreactive T cells, thus maintaining peripheral tolerance. Although abundant, demonstrate reduced function in MS patients. Taken together, along with the outcome of several studies regarding gut microbiota composition in CNS patients, the gut of MS individuals is characterized by microbial dysbiosis, ie impaired intestinal microbiota [123]. It is widely accepted that dietary habits affect the composition of human microbiota. Highfiber foods enhance gut populations of the Firmicutes and Bacteroidetes phyla, which produce short-chain fatty acids (SCFAs), which, in turn, suppress inflammation via Treg induction [129].

In 2016, the findings of a small randomized control trial (RCT) of a Mediterraneanstyle dietary intervention for MS were published. Thirty three Relapsing-Remitting MS (RRMS) patients were randomized into three groups: group 1 undertook a dietary intervention with vitamin D supplementation, group 2 started vitamin D without a dietary intervention, and group 3 underwent a dietary intervention with vitamin D and other nutritional supplements (including a multivitamin and fish oil supplement) [130]. The study failed to find a significant effect of the intervention on the Expanded Disability Status Score (EDSS) or the Fatigue Severity Scale (FSS).Very recently another study was published assessing adherence to MedDiet pattern, assessed based on alternate MedDietscore and the risk of a first clinical diagnosis of the precursor of MS, namely central nervous demyelination [131]. The Authors found that a Mediterranean diet, including unprocessed red meat, was associated with reduced risk of demyelination in this Australian adult population and concluded that adding up unprocessed red meat to a Mediterranean diet could exert beneficial effects for those at high risk of MS. Apart from MS and RA, there are other autoimmune diseases related 
with the gut microbiota, as Systemic lupus erythematosus (SLE), and the Inflammatory Bowel Disease [132-134].

Taken together, future studies on the role of Mediterranean diet components or as a whole on improvement of microbial dysbiosis, as well as reduction of autoimmunerelated inflammatory reactions would be of high importance. The diet appears to influence components of the innate and adaptive immunity, via a plethora of mechanisms, which act in isolation or in concert.

\section{Restoring microbiota through 'nutraceuticals'}

Nutraceuticals, a term coined by their "Godfather" Dr Stephen De Felice in 1989, contains both nutrition and pharmaceutical concepts and include products isolated or purified from foods. Established nutraceuticals include probiotics, prebiotics, omega-3 and -6 fatty acids, and others like polyphenols, phytoestrogens, flavonoids and antioxidants, with already recognized favourable effects under specific conditions $[135,136]$. Nutraceuticals are "related" to the human microbiota that includes 6 taxonomic bacterial phyla with Firmicutes and Bacteriodetes occupying the $90 \%$ of the host's colonized areas [137]. Nutraceuticals include probiotics, which WHO defines as "live micro-organisms" which, when administered in adequate amounts, confer a health benefit on the host. Probiotics produce short chain fatty acids (SCFAs), which are able to restore both population numbers and diversity of microbiota. Lactobacillus species may decrease or even prevent the symptoms of antibiotic associated diarrhea (AAD) [138], while a meta-analysis study showed positive effect of probiotics on AAD [139]. Furthermore, Lactobacillus, Bifidobacterium or Escherichia coli species have positive impact on host against metabolic diseases or gastrointestinal disorders [137]. 
Prebiotics, on the other hand, are "dietary carbohydrates stimulating the development of gut bacteria or probiotics post external administration, having advantageous results on the host" [140]. Breakdown of carbohydrates supply the body with SCFAs, - acetate, propionate and butyrate- which have a beneficial role on the composition and diversity of human microbiota [141]. Moreover, the advantageous impact of prebiotics on host health comprises alterations in gut microbiota composition, immune host capacity, energy production, enhanced mineral absorption and better functions of the intestinal barrier [142]. Administration of inulin or Fructo-oligosaccharides (FOS) on cancer patients demonstrated a positive impact of these components on gut populations of Lactobacillus and Bifidobacteria [143]. Ingredients in onions and garlic may have beneficial effect on particular gut microbial species populations, and, on the other hand, lethal effects on pathogens like E. coli and S. aureus [144]. Phytoestrogens include flavonoids, which regulate the intestinal barrier and own antimicrobial effect against pathogens, being characterized as alternative antibiotics [145]. Anthocyanins (also flavonoids), found in fruits like grapes and apples, may prevent a wide range of diseases [146]. Polyphenols, as quercetin, found in apples, grapes, onions, tomatoes, nuts and seeds, alters the gut microbiota in overweight mice fed with high-fat sucrose diet [147]. Resveratrol, another polyphenol taken as a food supplement regulates gut microbiota dysbiosis caused by high-fat diet, by enhancing growth of Lactobacillus and Bifidobacterium, raising the ratio of Bacteroidetes/Firmicutes and by hampering growth of E. faecalis[148]. Carvacrol and thymol, phenols in the aromatic plant Oregano vulgare, have antibacterial properties and ability to affect the gut microbiota and the immune status in animal models [149]. Use of omega-3 and -6 polyunsaturated fatty acids, as supplements, alter gut microbiota composition, by increasing Bacteroidetes/Firmicutes ratio, restrains growth of pathogenic bacteria like 
Helicobacter, Firmicutes, Pseudomonas sp, thus, avoiding immunological disturbances [144].

\section{Conclusions}

Taken together, there seems to be a close link among dietary habits, - both as foods or dietary supplements like nutraceuticals-, modulation of gut microbiota and, in turn, a critical role of human commensals on disease prevention/regulation, onset/development of immunological disturbances, as autoimmune, metabolic and other diseases. The Mediterranean diet is based on fruits, vegetables, seeds, nuts, fish, whose composition is rich in prebiotics, phytoestrogens as flavonoids, polyphenols and omega -3 and -6 polyunsaturated fats. Numerous studies have correlated Mediterranean dietary habits with beneficial effects on gut microbiota composition and possible positive connection with inflammatory diseases' risk of appearance and/or progression. Thus, it could be of critical importance to introduce or recommend/ or amplify the need for adopting Mediterranean dietary habits that may modulate microbial homeostasis, decrease the effects of pathogen invasions, and influence the inflammation pathway, for health's benefit. However, further studies, on its individual components and/or total/overall compounds of the Mediterranean diet "philosophy" on health's benefit via microbiota homeostasis should be conducted, to address the effect of the diet and its constituents in the prevention and clinical management of patients affect with specific autoimmune disorders. 


\section{References}

1. Willett, W.C.; Sacks, F.; Trichopoulou, A.; Drescher, G.; Ferro-Luzzi, A.; Helsing, E.; Trichopoulos, D. Mediterranean diet pyramid: a cultural model for healthy eating. Am. J. Clin. Nutr.1995, 61, 1402S-1406S.

2. Gifford, K.D. Dietary fats, eating guides, and public policy: history, critique, and recommendations. Am. J. Med.2002, 113 Suppl 9B, 89S-106S.

3. Senghor, B.; Sokhna, C.; Ruimy, R.; Lagier, J.-C. Gut microbiota diversity according to dietary habits and geographical provenance. Hum. Microbiome J.2018, 7-8, 1-9.

4. Kau, A.L.; Ahern, P.P.; Griffin, N.W.; Goodman, A.L.; Gordon, J.I. Human nutrition, the gut microbiome and the immune system. Nature2011, 474, 327-336.

5. Li, B.; Selmi, C.; Tang, R.; Gershwin, M.E.; Ma, X. The microbiome and autoimmunity: a paradigm from the gut-liver axis. Cell. Mol. Immunol.2018, 15, 595-609.

6. Vieira, S.M.; Pagovich, O.E.; Kriegel, M.A. Diet, microbiota and autoimmune diseases. Lupus2014, 23, 518-526.

7. Forsyth, C.; Kouvari, M.; D’Cunha, N.M.; Georgousopoulou, E.N.; Panagiotakos, D.B.; Mellor, D.D.; Kellett, J.; Naumovski, N. The effects of the Mediterranean diet on rheumatoid arthritis prevention and treatment: a systematic review of human prospective studies. Rheumatol. Int.2018, 38, 737-747.

8. Stamostergiou, J.; Theodoridis, X.; Ganochoriti, V.; Bogdanos, D.P.; Sakkas, L.I. The role of the Mediterranean diet in hyperuricemia and gout. MJR2018, 29, 21-25.

9. Estruch, R.; Ros, E.; Salas-Salvadó, J.; Covas, M.-I.; Corella, D.; Arós, F.; Gómez-Gracia, E.; Ruiz-Gutiérrez, V.; Fiol, M.; Lapetra, J.; et al. Primary Prevention of Cardiovascular Disease with a Mediterranean Diet Supplemented with Extra-Virgin Olive Oil or Nuts. $N$. Engl. J. Med.2018, 378, e34.

10. Martínez-González, M.A.; de la Fuente-Arrillaga, C.; Nunez-Cordoba, J.M.; BasterraGortari, F.J.; Beunza, J.J.; Vazquez, Z.; Benito, S.; Tortosa, A.; Bes-Rastrollo, M. Adherence to Mediterranean diet and risk of developing diabetes: prospective cohort study. BMJ2008, 336, 1348-1351.

11. Echeverría, G.; McGee, E.E.; Urquiaga, I.; Jiménez, P.; D’Acuña, S.; Villarroel, L.; Velasco, N.; Leighton, F.; Rigotti, A. Inverse Associations between a Locally Validated Mediterranean Diet Index, Overweight/Obesity, and Metabolic Syndrome in Chilean Adults. Nutrients2017, 9.

12. Kastorini, C.-M.; Milionis, H.J.; Esposito, K.; Giugliano, D.; Goudevenos, J.A.; Panagiotakos, D.B. The effect of Mediterranean diet on metabolic syndrome and its components: a meta-analysis of 50 studies and 534,906 individuals. J. Am. Coll. Cardiol.2011, 57, 1299-1313. 
13. Bonaccio, M.; Di Castelnuovo, A.; Costanzo, S.; Gialluisi, A.; Persichillo, M.; Cerletti, C.; Donati, M.B.; de Gaetano, G.; Iacoviello, L. Mediterranean diet and mortality in the elderly: a prospective cohort study and a meta-analysis. Br. J. Nutr.2018, 120, 841-854.

14. Godos, J.; Ferri, R.; Caraci, F.; Cosentino, F.I.I.; Castellano, S.; Shivappa, N.; Hebert, J.R.; Galvano, F.; Grosso, G. Dietary Inflammatory Index and Sleep Quality in Southern Italian Adults. Nutrients2019, 11.

15. Jennings, A.; Cashman, K.D.; Gillings, R.; Cassidy, A.; Tang, J.; Fraser, W.; Dowling, K.G.; Hull, G.L.J.; Berendsen, A.A.M.; de Groot, L.C.P.G.M.; et al. A Mediterranean-like dietary pattern with vitamin D3 $(10 \mu \mathrm{g} / \mathrm{d})$ supplements reduced the rate of bone loss in older Europeans with osteoporosis at baseline: results of a 1-y randomized controlled trial. Am. J. Clin. Nutr.2018, 108, 633-640.

16. Leung, C.W.; Fung, T.T.; McEvoy, C.T.; Lin, J.; Epel, E.S. Diet Quality Indices and Leukocyte Telomere Length Among Healthy US Adults: Data From the National Health and Nutrition Examination Survey, 1999-2002. Am. J. Epidemiol.2018, 187, 2192-2201.

17. Pagliai, G.; Sofi, F.; Vannetti, F.; Caiani, S.; Pasquini, G.; Molino Lova, R.; Cecchi, F.; Sorbi, S.; Macchi, C. Mediterranean Diet, Food Consumption and Risk of Late-Life Depression: The Mugello Study. J. Nutr. Health Aging2018, 22, 569-574.

18. Ma, J.; Hennein, R.; Liu, C.; Long, M.T.; Hoffmann, U.; Jacques, P.F.; Lichtenstein, A.H.; Hu, F.B.; Levy, D. Improved Diet Quality Associates With Reduction in Liver Fat, Particularly in Individuals With High Genetic Risk Scores for Nonalcoholic Fatty Liver Disease. Gastroenterology2018, 155, 107-117.

19. Castelló, A.; Boldo, E.; Amiano, P.; Castaño-Vinyals, G.; Aragonés, N.; Gómez-Acebo, I.; Peiró, R.; Jimenez-Moleón, J.J.; Alguacil, J.; Tardón, A.; et al. Mediterranean Dietary Pattern is Associated with Low Risk of Aggressive Prostate Cancer: MCC-Spain Study. $J$. Urol.2018, 199, 430-437.

20. Haslam, A.; Robb, S.W.; Hébert, J.R.; Huang, H.; Ebell, M.H. Greater adherence to a Mediterranean diet is associated with lower prevalence of colorectal adenomas in men of all races. Nutr. Res. N. Y. N2017, 48, 76-84.

21. Assaf-Balut, C.; García de la Torre, N.; Durán, A.; Fuentes, M.; Bordiú, E.; Del Valle, L.; Familiar, C.; Ortolá, A.; Jiménez, I.; Herraiz, M.A.; et al. A Mediterranean diet with additional extra virgin olive oil and pistachios reduces the incidence of gestational diabetes mellitus (GDM): A randomized controlled trial: The St. Carlos GDM prevention study. PloS One2017, 12, e0185873.

22. Sotos-Prieto, M.; Bhupathiraju, S.N.; Mattei, J.; Fung, T.T.; Li, Y.; Pan, A.; Willett, W.C.; Rimm, E.B.; Hu, F.B. Association of Changes in Diet Quality with Total and CauseSpecific Mortality. N. Engl. J. Med.2017, 377, 143-153. 
23. Crous-Bou, M.; Fung, T.T.; Prescott, J.; Julin, B.; Du, M.; Sun, Q.; Rexrode, K.M.; Hu, F.B.; De Vivo, I. Mediterranean diet and telomere length in Nurses' Health Study: population based cohort study. BMJ2014, 349, g6674.

24. Relman, D.A. Microbiology: Learning about who we are. Nature2012, 486, 194-195.

25. Muegge, B.D.; Kuczynski, J.; Knights, D.; Clemente, J.C.; González, A.; Fontana, L.; Henrissat, B.; Knight, R.; Gordon, J.I. Diet drives convergence in gut microbiome functions across mammalian phylogeny and within humans. Science2011, 332, 970-974.

26. Ley, R.E.; Hamady, M.; Lozupone, C.; Turnbaugh, P.J.; Ramey, R.R.; Bircher, J.S.; Schlegel, M.L.; Tucker, T.A.; Schrenzel, M.D.; Knight, R.; et al. Evolution of mammals and their gut microbes. Science 2008, 320, 1647-1651.

27. Kashtanova, D.A.; Popenko, A.S.; Tkacheva, O.N.; Tyakht, A.B.; Alexeev, D.G.; Boytsov, S.A. Association between the gut microbiota and diet: Fetal life, early childhood, and further life. Nutr. Burbank Los Angel. Cty. Calif2016, 32, 620-627.

28. Houghton, D.; Stewart, C.J.; Day, C.P.; Trenell, M. Gut Microbiota and Lifestyle Interventions in NAFLD. Int. J. Mol. Sci.2016, 17, 447.

29. Murphy, E.F.; Cotter, P.D.; Healy, S.; Marques, T.M.; O’Sullivan, O.; Fouhy, F.; Clarke, S.F.; O'Toole, P.W.; Quigley, E.M.; Stanton, C.; et al. Composition and energy harvesting capacity of the gut microbiota: relationship to diet, obesity and time in mouse models. Gut2010, 59, 1635-1642.

30. Turnbaugh, P.J.; Bäckhed, F.; Fulton, L.; Gordon, J.I. Diet-induced obesity is linked to marked but reversible alterations in the mouse distal gut microbiome. Cell Host Microbe2008, 3, 213-223.

31. Hildebrandt, M.A.; Hoffmann, C.; Sherrill-Mix, S.A.; Keilbaugh, S.A.; Hamady, M.; Chen, Y.-Y.; Knight, R.; Ahima, R.S.; Bushman, F.; Wu, G.D. High-fat diet determines the composition of the murine gut microbiome independently of obesity. Gastroenterology2009, 137, 1716-1724.e1-2.

32. Daniel, H.; Gholami, A.M.; Berry, D.; Desmarchelier, C.; Hahne, H.; Loh, G.; Mondot, S.; Lepage, P.; Rothballer, M.; Walker, A.; et al. High-fat diet alters gut microbiota physiology in mice. ISME J.2014, 8, 295-308.

33. de Wit, N.J.W.; Afman, L.A.; Mensink, M.; Müller, M. Phenotyping the effect of diet on non-alcoholic fatty liver disease. J. Hepatol.2012, 57, 1370-1373.

34. Mujico, J.R.; Baccan, G.C.; Gheorghe, A.; Díaz, L.E.; Marcos, A. Changes in gut microbiota due to supplemented fatty acids in diet-induced obese mice. Br. J. Nutr.2013, $110,711-720$.

35. McAllan, L.; Skuse, P.; Cotter, P.D.; O’Connor, P.; Cryan, J.F.; Ross, R.P.; Fitzgerald, G.; Roche, H.M.; Nilaweera, K.N. Protein quality and the protein to carbohydrate ratio within 
a high fat diet influences energy balance and the gut microbiota in C57BL/6J mice. PloS One2014, 9, e88904.

36. Hansen, L.B.S.; Roager, H.M.; Søndertoft, N.B.; Gøbel, R.J.; Kristensen, M.; VallèsColomer, M.; Vieira-Silva, S.; Ibrügger, S.; Lind, M.V.; Mærkedahl, R.B.; et al. A lowgluten diet induces changes in the intestinal microbiome of healthy Danish adults. Nat. Commun.2018, 9, 4630.

37. Ferrocino, I.; Di Cagno, R.; De Angelis, M.; Turroni, S.; Vannini, L.; Bancalari, E.; Rantsiou, K.; Cardinali, G.; Neviani, E.; Cocolin, L. Fecal Microbiota in Healthy Subjects Following Omnivore, Vegetarian and Vegan Diets: Culturable Populations and rRNA DGGE Profiling. PloS One2015, 10, e0128669.

38. Rothschild, D.; Weissbrod, O.; Barkan, E.; Kurilshikov, A.; Korem, T.; Zeevi, D.; Costea, P.I.; Godneva, A.; Kalka, I.N.; Bar, N.; et al. Environment dominates over host genetics in shaping human gut microbiota. Nature 2018, 555, 210-215.

39. Obregon-Tito, A.J.; Tito, R.Y.; Metcalf, J.; Sankaranarayanan, K.; Clemente, J.C.; Ursell, L.K.; Zech Xu, Z.; Van Treuren, W.; Knight, R.; Gaffney, P.M.; et al. Subsistence strategies in traditional societies distinguish gut microbiomes. Nat. Commun.2015, 6, 6505.

40. Vangay, P.; Johnson, A.J.; Ward, T.L.; Al-Ghalith, G.A.; Shields-Cutler, R.R.; Hillmann, B.M.; Lucas, S.K.; Beura, L.K.; Thompson, E.A.; Till, L.M.; et al. US Immigration Westernizes the Human Gut Microbiome. Cell2018, 175, 962-972.e10.

41. O'Hara, A.M.; Shanahan, F. The gut flora as a forgotten organ. EMBO Rep.2006, 7, 688 693.

42. Ursell, L.K.; Haiser, H.J.; Van Treuren, W.; Garg, N.; Reddivari, L.; Vanamala, J.; Dorrestein, P.C.; Turnbaugh, P.J.; Knight, R. The intestinal metabolome: an intersection between microbiota and host. Gastroenterology2014, 146, 1470-1476.

43. Cash, H.L.; Whitham, C.V.; Behrendt, C.L.; Hooper, L.V. Symbiotic bacteria direct expression of an intestinal bactericidal lectin. Science2006, 313, 1126-1130.

44. Gill, S.R.; Pop, M.; Deboy, R.T.; Eckburg, P.B.; Turnbaugh, P.J.; Samuel, B.S.; Gordon, J.I.; Relman, D.A.; Fraser-Liggett, C.M.; Nelson, K.E. Metagenomic analysis of the human distal gut microbiome. Science2006, 312, 1355-1359.

45. Hooper, L.V.; Stappenbeck, T.S.; Hong, C.V.; Gordon, J.I. Angiogenins: a new class of microbicidal proteins involved in innate immunity. Nat. Immunol.2003, 4, 269-273.

46. Rakoff-Nahoum, S.; Medzhitov, R. Innate immune recognition of the indigenous microbial flora. Mucosal Immunol.2008, 1 Suppl 1, S10-14.

47. Macpherson, A.J.; Harris, N.L. Interactions between commensal intestinal bacteria and the immune system. Nat. Rev. Immunol.2004, 4, 478-485.

48. Thaiss, C.A.; Zmora, N.; Levy, M.; Elinav, E. The microbiome and innate immunity. Nature2016, 535, 65-74. 
49. Miller, F.W.; Pollard, K.M.; Parks, C.G.; Germolec, D.R.; Leung, P.S.C.; Selmi, C.; Humble, M.C.; Rose, N.R. Criteria for environmentally associated autoimmune diseases. J. Autoimmun.2012, 39, 253-258.

50. Ramos-Casals, M.; Brito-Zerón, P.; Kostov, B.; Sisó-Almirall, A.; Bosch, X.; Buss, D.; Trilla, A.; Stone, J.H.; Khamashta, M.A.; Shoenfeld, Y. Google-driven search for big data in autoimmune geoepidemiology: analysis of 394,827 patients with systemic autoimmune diseases. Autoimmun. Rev.2015, 14, 670-679.

51. Chervonsky, A.V. Microbiota and autoimmunity. Cold Spring Harb. Perspect. Biol.2013, 5, a007294.

52. Belkaid, Y.; Hand, T.W. Role of the microbiota in immunity and inflammation. Cell2014, 157, 121-141.

53. Shamriz, O.; Mizrahi, H.; Werbner, M.; Shoenfeld, Y.; Avni, O.; Koren, O. Microbiota at the crossroads of autoimmunity. Autoimmun. Rev.2016, 15, 859-869.

54. De Luca, F.; Shoenfeld, Y. The microbiome in autoimmune diseases. Clin. Exp. Immunol.2019, 195, 74-85.

55. Agmon-Levin, N.; Ram, M.; Barzilai, O.; Porat-Katz, B.S.; Parikman, R.; Selmi, C.; Gershwin, M.E.; Anaya, J.-M.; Youinou, P.; Bizzaro, N.; et al. Prevalence of hepatitis C serum antibody in autoimmune diseases. J. Autoimmun.2009, 32, 261-266.

56. Getts, D.R.; Chastain, E.M.L.; Terry, R.L.; Miller, S.D. Virus infection, antiviral immunity, and autoimmunity. Immunol. Rev.2013, 255, 197-209.

57. Guilherme, L.; Kalil, J.; Cunningham, M. Molecular mimicry in the autoimmune pathogenesis of rheumatic heart disease. Autoimmunity2006, 39, 31-39.

58. Vojdani, A. A Potential Link between Environmental Triggers and Autoimmunity. Autoimmune Dis.2014, 2014, 437231.

59. Vanderlugt, C.J.; Miller, S.D. Epitope spreading. Curr. Opin. Immunol.1996, 8, 831-836.

60. Cunningham, M.W. Pathogenesis of group A streptococcal infections. Clin. Microbiol. Rev.2000, 13, 470-511.

61. Bogdanos, D.P.; Sakkas, L.I. From microbiome to infectome in autoimmunity. Curr. Opin. Rheumatol.2017, 29, 369-373.

62. Polymeros, D.; Tsiamoulos, Z.P.; Koutsoumpas, A.L.; Smyk, D.S.; Mytilinaiou, M.G.; Triantafyllou, K.; Bogdanos, D.P.; Ladas, S.D. Bioinformatic and immunological analysis reveals lack of support for measles virus related mimicry in Crohn's disease. BMC Med.2014, 12, 139.

63. Ehser, J.; Holdener, M.; Christen, S.; Bayer, M.; Pfeilschifter, J.M.; Hintermann, E.; Bogdanos, D.; Christen, U. Molecular mimicry rather than identity breaks T-cell tolerance in the CYP2D6 mouse model for human autoimmune hepatitis. J. Autoimmun.2013, 42, $39-49$. 
64. Koutsoumpas, A.; Polymeros, D.; Tsiamoulos, Z.; Smyk, D.; Karamanolis, G.; Triantafyllou, K.; Rigopoulou, E.I.; Forbes, A.; Vergani, D.; Bogdanos, D.P.; et al. Peculiar antibody reactivity to human connexin 37 and its microbial mimics in patients with Crohn's disease. J. Crohns Colitis2011, 5, 101-109.

65. Koutsoumpas, A.; Mytilinaiou, M.; Polymeros, D.; Dalekos, G.N.; Bogdanos, D.P. AntiHelicobacter pylori antibody responses specific for VacA do not trigger primary biliary cirrhosis-specific antimitochondrial antibodies. Eur. J. Gastroenterol. Hepatol.2009, 21, 1220.

66. Bogdanos, D.-P.; Rigopoulou, E.I. Viral/self-mimicry and immunological cross-reactivity as a trigger of hepatic $\mathrm{C}$ virus associated autoimmune diabetes. Diabetes Res. Clin. Pract.2007, 77, 155-156.

67. Bogdanos, D.-P.; Koutsoumpas, A.; Baum, H.; Vergani, D. Borrelia Burgdorferi: a new self-mimicking trigger in primary biliary cirrhosis. Dig. Liver Dis. Off. J. Ital. Soc. Gastroenterol. Ital. Assoc. Study Liver2006, 38, 781-782; author reply 782-783.

68. Polymeros, D.; Bogdanos, D.P.; Day, R.; Arioli, D.; Vergani, D.; Forbes, A. Does crossreactivity between mycobacterium avium paratuberculosis and human intestinal antigens characterize Crohn's disease? Gastroenterology2006, 131, 85-96.

69. Bogdanos, D.-P.; Smith, H.; Ma, Y.; Baum, H.; Mieli-Vergani, G.; Vergani, D. A study of molecular mimicry and immunological cross-reactivity between hepatitis B surface antigen and myelin mimics. Clin. Dev. Immunol.2005, 12, 217-224.

70. Muratori, L.; Bogdanos, D.P.; Muratori, P.; Lenzi, M.; Granito, A.; Ma, Y.; Mieli-Vergani, G.; Bianchi, F.B.; Vergani, D. Susceptibility to thyroid disorders in hepatitis C. Clin. Gastroenterol. Hepatol. Off. Clin. Pract. J. Am. Gastroenterol. Assoc. 2005, 3, 595-603.

71. Bogdanos, D.-P.; Baum, H.; Gunsar, F.; Arioli, D.; Polymeros, D.; Ma, Y.; Burroughs, A.K.; Vergani, D. Extensive homology between the major immunodominant mitochondrial antigen in primary biliary cirrhosis and Helicobacter pylori does not lead to immunological cross-reactivity. Scand. J. Gastroenterol.2004, 39, 981-987.

72. Bogdanos, D.-P.; Pares, A.; Baum, H.; Caballeria, L.; Rigopoulou, E.I.; Ma, Y.; Burroughs, A.K.; Rodes, J.; Vergani, D. Disease-specific cross-reactivity between mimicking peptides of heat shock protein of Mycobacterium gordonae and dominant epitope of E2 subunit of pyruvate dehydrogenase is common in Spanish but not British patients with primary biliary cirrhosis. J. Autoimmun.2004, 22, 353-362.

73. Bogdanos, D.-P.; Lenzi, M.; Okamoto, M.; Rigopoulou, E.I.; Muratori, P.; Ma, Y.; Muratori, L.; Tsantoulas, D.; Mieli- Vergani, G.; Bianchi, F.B.; et al. Multiple viral/self immunological cross-reactivity in liver kidney microsomal antibody positive hepatitis $\mathrm{C}$ virus infected patients is associated with the possession of HLA B51. Int. J. Immunopathol. Pharmacol.2004, 17, 83-92. 
74. Bogdanos, D.-P.; Baum, H.; Grasso, A.; Okamoto, M.; Butler, P.; Ma, Y.; Rigopoulou, E.; Montalto, P.; Davies, E.T.; Burroughs, A.K.; et al. Microbial mimics are major targets of crossreactivity with human pyruvate dehydrogenase in primary biliary cirrhosis. $J$. Hepatol.2004, 40, 31-39.

75. Gregorio, G.V.; Choudhuri, K.; Ma, Y.; Pensati, P.; Iorio, R.; Grant, P.; Garson, J.; Bogdanos, D.P.; Vegnente, A.; Mieli-Vergani, G.; et al. Mimicry between the hepatitis C virus polyprotein and antigenic targets of nuclear and smooth muscle antibodies in chronic hepatitis C virus infection. Clin. Exp. Immunol.2003, 133, 404-413.

76. Bogdanos, D.-P.; Baum, H.; Sharma, U.C.; Grasso, A.; Ma, Y.; Burroughs, A.K.; Vergani, D. Antibodies against homologous microbial caseinolytic proteases $\mathrm{P}$ characterise primary biliary cirrhosis. J. Hepatol.2002, 36, 14-21.

77. Bogdanos, D.P.; Choudhuri, K.; Vergani, D. Molecular mimicry and autoimmune liver disease: virtuous intentions, malign consequences. Liver 2001, 21, 225-232.

78. Baum, H.; Bogdanos, D.P.; Vergani, D. Antibodies to Clp protease in primary biliary cirrhosis: possible role of a mimicking T-cell epitope. J. Hepatol.2001, 34, 785-787.

79. Bogdanos, D.P.; Mieli-Vergani, G.; Vergani, D. Virus, liver and autoimmunity. Dig. Liver Dis. Off. J. Ital. Soc. Gastroenterol. Ital. Assoc. Study Liver2000, 32, 440-446.

80. Fujinami, R.S.; von Herrath, M.G.; Christen, U.; Whitton, J.L. Molecular mimicry, bystander activation, or viral persistence: infections and autoimmune disease. Clin. Microbiol. Rev.2006, 19, 80-94.

81. Widmer, R.J.; Flammer, A.J.; Lerman, L.O.; Lerman, A. The Mediterranean diet, its components, and cardiovascular disease. Am. J. Med.2015, 128, 229-238.

82. Azuma, M.M.; Gomes-Filho, J.E.; Ervolino, E.; Cardoso, C. de B.M.; Pipa, C.B.; Kawai, T.; Conti, L.C.; Cintra, L.T.A. Omega-3 Fatty Acids Reduce Inflammation in Rat Apical Periodontitis. J. Endod.2018, 44, 604-608.

83. Kopf, J.C.; Suhr, M.J.; Clarke, J.; Eyun, S.-I.; Riethoven, J.-J.M.; Ramer-Tait, A.E.; Rose, D.J. Role of whole grains versus fruits and vegetables in reducing subclinical inflammation and promoting gastrointestinal health in individuals affected by overweight and obesity: a randomized controlled trial. Nutr. J.2018, 17, 72.

84. Koloverou, E.; Panagiotakos, D.B.; Pitsavos, C.; Chrysohoou, C.; Georgousopoulou, E.N.; Grekas, A.; Christou, A.; Chatzigeorgiou, M.; Skoumas, I.; Tousoulis, D.; et al. Adherence to Mediterranean diet and 10-year incidence (2002-2012) of diabetes: correlations with inflammatory and oxidative stress biomarkers in the ATTICA cohort study. Diabetes Metab. Res. Rev.2016, 32, 73-81.

85. Neale, E.P.; Batterham, M.J.; Tapsell, L.C. Consumption of a healthy dietary pattern results in significant reductions in C-reactive protein levels in adults: a meta-analysis. Nutr. Res. N. Y. N2016, 36, 391-401. 
86. Sköldstam, L.; Hagfors, L.; Johansson, G. An experimental study of a Mediterranean diet intervention for patients with rheumatoid arthritis. Ann. Rheum. Dis.2003, 62, 208-214.

87. Porras, M.; Rada, G.; Durán, J. Effects of Mediterranean diet on the treatment of rheumatoid arthritis. Medwave2019, 19, e7640.

88. García-Morales, J.M.; Lozada-Mellado, M.; Hinojosa-Azaola, A.; Llorente, L.; OgataMedel, M.; Pineda-Juárez, J.A.; Alcocer-Varela, J.; Cervantes-Gaytán, R.; CastilloMartínez, L. Effect of a Dynamic Exercise Program in Combination With Mediterranean Diet on Quality of Life in Women With Rheumatoid Arthritis. J. Clin. Rheumatol. Pract. Rep. Rheum. Musculoskelet. Dis.2019.

89. Johansson, K.; Askling, J.; Alfredsson, L.; Di Giuseppe, D.; EIRA study group Mediterranean diet and risk of rheumatoid arthritis: a population-based case-control study. Arthritis Res. Ther.2018, 20, 175.

90. Hu, Y.; Costenbader, K.H.; Gao, X.; Hu, F.B.; Karlson, E.W.; Lu, B. Mediterranean diet and incidence of rheumatoid arthritis in women. Arthritis Care Res.2015, 67, 597-606.

91. McKellar, G.; Morrison, E.; McEntegart, A.; Hampson, R.; Tierney, A.; Mackle, G.; Scoular, J.; Scott, J.A.; Capell, H.A. A pilot study of a Mediterranean-type diet intervention in female patients with rheumatoid arthritis living in areas of social deprivation in Glasgow. Ann. Rheum. Dis.2007, 66, 1239-1243.

92. Hagfors, L.; Leanderson, P.; Sköldstam, L.; Andersson, J.; Johansson, G. Antioxidant intake, plasma antioxidants and oxidative stress in a randomized, controlled, parallel, Mediterranean dietary intervention study on patients with rheumatoid arthritis. Nutr. $J .2003,2,5$.

93. Hagfors, L.; Nilsson, I.; Sköldstam, L.; Johansson, G. Fat intake and composition of fatty acids in serum phospholipids in a randomized, controlled, Mediterranean dietary intervention study on patients with rheumatoid arthritis. Nutr. Metab.2005, 2, 26.

94. Michalsen, A.; Riegert, M.; Lüdtke, R.; Bäcker, M.; Langhorst, J.; Schwickert, M.; Dobos, G.J. Mediterranean diet or extended fasting's influence on changing the intestinal microflora, immunoglobulin A secretion and clinical outcome in patients with rheumatoid arthritis and fibromyalgia: an observational study. BMC Complement. Altern. Med.2005, $5,22$.

95. Pagliai, G.; Russo, E.; Niccolai, E.; Dinu, M.; Di Pilato, V.; Magrini, A.; Bartolucci, G.; Baldi, S.; Menicatti, M.; Giusti, B.; et al. Influence of a 3-month low-calorie Mediterranean diet compared to the vegetarian diet on human gut microbiota and SCFA: the CARDIVEG Study. Eur. J. Nutr. 2019.

96. Abendroth, A.; Michalsen, A.; Lüdtke, R.; Rüffer, A.; Musial, F.; Dobos, G.J.; Langhorst, J. Changes of Intestinal Microflora in Patients with Rheumatoid Arthritis during Fasting or a Mediterranean Diet. Forsch. Komplementarmedizin 20062010, 17, 307-313. 
97. Gutiérrez-Díaz, I.; Fernández-Navarro, T.; Sánchez, B.; Margolles, A.; González, S. Mediterranean diet and faecal microbiota: a transversal study. Food Funct.2016, 7, $2347-$ 2356.

98. De Filippis, F.; Pellegrini, N.; Vannini, L.; Jeffery, I.B.; La Storia, A.; Laghi, L.; Serrazanetti, D.I.; Di Cagno, R.; Ferrocino, I.; Lazzi, C.; et al. High-level adherence to a Mediterranean diet beneficially impacts the gut microbiota and associated metabolome. Gut2016, 65, 1812-1821.

99. Mitsou, E.K.; Kakali, A.; Antonopoulou, S.; Mountzouris, K.C.; Yannakoulia, M.; Panagiotakos, D.B.; Kyriacou, A. Adherence to the Mediterranean diet is associated with the gut microbiota pattern and gastrointestinal characteristics in an adult population. $B r . J$. Nutr.2017, 117, 1645-1655.

100. De Santis, S.; Cavalcanti, E.; Mastronardi, M.; Jirillo, E.; Chieppa, M. Nutritional Keys for Intestinal Barrier Modulation. Front. Immunol.2015, 6, 612.

101. Lerner, A.; Patricia, J.; Matthias, T. Nutrients, Bugs and Us: The Short-chain Fatty Acids Story in Celiac Disease. Int. J. Celiac Dis.2016, 4, 92-94.

102. Hui, W.; Yu, D.; Cao, Z.; Zhao, X. Butyrate inhibit collagen-induced arthritis via Treg/IL-10/Th17 axis. Int. Immunopharmacol.2019, 68, 226-233.

103. Obeid, R.; Awwad, H.M.; Keller, M.; Geisel, J. Trimethylamine-N-oxide and its biological variations in vegetarians. Eur. J. Nutr.2017, 56, 2599-2609.

104. Breban, M.; Tap, J.; Leboime, A.; Said-Nahal, R.; Langella, P.; Chiocchia, G.; Furet, J.-P.; Sokol, H. Faecal microbiota study reveals specific dysbiosis in spondyloarthritis. Ann. Rheum. Dis.2017, 76, 1614-1622.

105. Scher, J.U.; Sczesnak, A.; Longman, R.S.; Segata, N.; Ubeda, C.; Bielski, C.; Rostron, T.; Cerundolo, V.; Pamer, E.G.; Abramson, S.B.; et al. Expansion of intestinal Prevotella copri correlates with enhanced susceptibility to arthritis. eLife 2013, 2, e01202.

106. Pianta, A.; Arvikar, S.; Strle, K.; Drouin, E.E.; Wang, Q.; Costello, C.E.; Steere, A.C. Evidence of the Immune Relevance of Prevotella copri, a Gut Microbe, in Patients With Rheumatoid Arthritis. Arthritis Rheumatol. Hoboken NJ2017, 69, 964-975.

107. Vaahtovuo, J.; Munukka, E.; Korkeamäki, M.; Luukkainen, R.; Toivanen, P. Fecal microbiota in early rheumatoid arthritis. J. Rheumatol.2008, 35, 1500-1505.

108. Alpizar-Rodriguez, D.; Lesker, T.R.; Gronow, A.; Gilbert, B.; Raemy, E.; Lamacchia, C.; Gabay, C.; Finckh, A.; Strowig, T. Prevotella copri in individuals at risk for rheumatoid arthritis. Ann. Rheum. Dis.2019, 78, 590-593.

109. Wells, P.M.; Williams, F.M.K.; Matey-Hernandez, M.L.; Menni, C.; Steves, C.J. 'RA and the microbiome: do host genetic factors provide the link? J. Autoimmun.2019, 99, 104115. 
110. Schwenzer, A.; Quirke, A.-M.; Marzeda, A.M.; Wong, A.; Montgomery, A.B.; Sayles, H.R.; Eick, S.; Gawron, K.; Chomyszyn-Gajewska, M.; Lazarz-Bartyzel, K.; et al. Association of Distinct Fine Specificities of Anti-Citrullinated Peptide Antibodies With Elevated Immune Responses to Prevotella intermedia in a Subgroup of Patients With Rheumatoid Arthritis and Periodontitis. Arthritis Rheumatol. Hoboken NJ2017, 69, 23032313.

111. Chung, Y.L.; Rider, L.G.; Bell, J.D.; Summers, R.M.; Zemel, L.S.; Rennebohm, R.M.; Passo, M.H.; Hicks, J.; Miller, F.W.; Scott, D.L. Muscle metabolites, detected in urine by proton spectroscopy, correlate with disease damage in juvenile idiopathic inflammatory myopathies. Arthritis Rheumatol.2005, 53, 565-570.

112. Asteriou, E.; Gkoutzourelas, A.; Mavropoulos, A.; Katsiari, C.; Sakkas, L.I.; Bogdanos, D.P. Curcumin for the Management of Periodontitis and Early ACPA-Positive Rheumatoid Arthritis: Killing Two Birds with One Stone. Nutrients2018, 10.

113. Kelepouri, D.; Mavropoulos, A.; Bogdanos, D.P.; Sakkas, L.I. The Role of Flavonoids in Inhibiting Th17 Responses in Inflammatory Arthritis. J. Immunol. Res.2018, 2018, 9324357.

114. Sakkas, L.I.; Bogdanos, D.P. Multiple hit infection and autoimmunity: the dysbiotic microbiota-ACPA connection in rheumatoid arthritis. Curr. Opin. Rheumatol.2018, 30, 403-409.

115. Pianta, A.; Arvikar, S.L.; Strle, K.; Drouin, E.E.; Wang, Q.; Costello, C.E.; Steere, A.C. Two rheumatoid arthritis-specific autoantigens correlate microbial immunity with autoimmune responses in joints. J. Clin. Invest.2017, 127, 2946-2956.

116. Obando-Pereda, G.A. GAKG-RGEKG an Epitope That Provokes Immune CrossReactivity between Prevotella sp. and Human Collagen: Evidence of Molecular Mimicry in Chronic Periodontitis. Autoimmune Dis.2016, 2016, 5472320.

117. McInnes, I.B.; Schett, G. The pathogenesis of rheumatoid arthritis. N. Engl. J. Med.2011, 365, 2205-2219.

118. Oen, K.; Postl, B.; Chalmers, I.M.; Ling, N.; Schroeder, M.L.; Baragar, F.D.; Martin, L.; Reed, M.; Major, P. Rheumatic diseases in an Inuit population. Arthritis Rheum.1986, $29,65-74$.

119. Mulvad, G.; Pedersen, H.S.; Hansen, J.C.; Dewailly, E.; Jul, E.; Pedersen, M.; Deguchi, Y.; Newman, W.P.; Malcom, G.T.; Tracy, R.E.; et al. The Inuit diet. Fatty acids and antioxidants, their role in ischemic heart disease, and exposure to organochlorines and heavy metals. An international study. Arctic Med. Res.1996, 55 Suppl 1, 20-24.

120. Yue, M.; Tao, Y.; Fang, Y.; Lian, X.; Zhang, Q.; Xia, Y.; Wei, Z.; Dai, Y. The gut microbiota modulator berberine ameliorates collagen-induced arthritis in rats by 
facilitating the generation of butyrate and adjusting the intestinal hypoxia and nitrate supply. FASEB J. Off. Publ. Fed. Am. Soc. Exp. Biol.2019, fj201900425RR.

121. Garcia-Mantrana, I.; Selma-Royo, M.; Alcantara, C.; Collado, M.C. Shifts on Gut Microbiota Associated to Mediterranean Diet Adherence and Specific Dietary Intakes on General Adult Population. Front. Microbiol.2018, 9, 890.

122. Shankar, V.; Gouda, M.; Moncivaiz, J.; Gordon, A.; Reo, N.V.; Hussein, L.; Paliy, O. Differences in Gut Metabolites and Microbial Composition and Functions between Egyptian and U.S. Children Are Consistent with Their Diets. mSystems2017, 2.

123. Colpitts, S.L.; Kasper, L.H. Influence of the Gut Microbiome on Autoimmunity in the Central Nervous System. J. Immunol. Baltim. Md 19502017, 198, 596-604.

124. Hirschberg, S.; Gisevius, B.; Duscha, A.; Haghikia, A. Implications of Diet and The Gut Microbiome in Neuroinflammatory and Neurodegenerative Diseases. Int. J. Mol. Sci.2019, 20.

125. Berer, K.; Mues, M.; Koutrolos, M.; Rasbi, Z.A.; Boziki, M.; Johner, C.; Wekerle, H.; Krishnamoorthy, G. Commensal microbiota and myelin autoantigen cooperate to trigger autoimmune demyelination. Nature2011, 479, 538-541.

126. Lee, Y.K.; Menezes, J.S.; Umesaki, Y.; Mazmanian, S.K. Proinflammatory T-cell responses to gut microbiota promote experimental autoimmune encephalomyelitis. Proc. Natl. Acad. Sci. U. S. A.2011, 108 Suppl 1, 4615-4622.

127. Dos Passos, G.R.; Sato, D.K.; Becker, J.; Fujihara, K. Th17 Cells Pathways in Multiple Sclerosis and Neuromyelitis Optica Spectrum Disorders: Pathophysiological and Therapeutic Implications. Mediators Inflamm.2016, 2016, 5314541.

128. Chewning, J.H.; Weaver, C.T. Development and survival of Th17 cells within the intestines: the influence of microbiome- and diet-derived signals. J. Immunol. Baltim. Md 19502014, 193, 4769-4777.

129. Smith, P.M.; Howitt, M.R.; Panikov, N.; Michaud, M.; Gallini, C.A.; Bohlooly-Y, M.; Glickman, J.N.; Garrett, W.S. The microbial metabolites, short-chain fatty acids, regulate colonic Treg cell homeostasis. Science2013, 341, 569-573.

130. Riccio, P.; Rossano, R.; Larocca, M.; Trotta, V.; Mennella, I.; Vitaglione, P.; Ettorre, M.; Graverini, A.; De Santis, A.; Di Monte, E.; et al. Anti-inflammatory nutritional intervention in patients with relapsing-remitting and primary-progressive multiple sclerosis: A pilot study. Exp. Biol. Med. Maywood NJ2016, 241, 620-635.

131. Black, L.J.; Baker, K.; Ponsonby, A.-L.; van der Mei, I.; Lucas, R.M.; Pereira, G.; Ausimmune Investigator Group A Higher Mediterranean Diet Score, Including Unprocessed Red Meat, Is Associated with Reduced Risk of Central Nervous System Demyelination in a Case-Control Study of Australian Adults. J. Nutr.2019, 149, 13851392. 
132. Ruiz, L.; López, P.; Suárez, A.; Sánchez, B.; Margolles, A. The role of gut microbiota in lupus: what we know in 2018? Expert Rev. Clin. Immunol.2018, 14, 787-792.

133. Luo, X.M.; Edwards, M.R.; Mu, Q.; Yu, Y.; Vieson, M.D.; Reilly, C.M.; Ahmed, S.A.; Bankole, A.A. Gut Microbiota in Human Systemic Lupus Erythematosus and a Mouse Model of Lupus. Appl. Environ. Microbiol.2018, 84.

134. Zuo, T.; Ng, S.C. The Gut Microbiota in the Pathogenesis and Therapeutics of Inflammatory Bowel Disease. Front. Microbiol.2018, 9, 2247.

135. Chauhan, B.; Kumar, G.; Kalam, N.; Ansari, S.H. Current concepts and prospects of herbal nutraceutical: A review. J. Adv. Pharm. Technol. Res.2013, 4, 4-8.

136. Stauffer, J. Nutraceuticals. Cereal Foods World1999, 44, 115-116.

137. Woting, A.; Blaut, M. The Intestinal Microbiota in Metabolic Disease. Nutrients2016, $8,202$.

138. Park, M.S.; Kwon, B.; Ku, S.; Ji, G.E. The Efficacy of Bifidobacterium longum BORI and Lactobacillus acidophilus AD031 Probiotic Treatment in Infants with Rotavirus Infection. Nutrients2017, 9.

139. Johnston, B.C.; Goldenberg, J.Z.; Vandvik, P.O.; Sun, X.; Guyatt, G.H. Probiotics for the prevention of pediatric antibiotic-associated diarrhea. Cochrane Database Syst. Rev.2011, CD004827.

140. Bindels, L.B.; Neyrinck, A.M.; Salazar, N.; Taminiau, B.; Druart, C.; Muccioli, G.G.; François, E.; Blecker, C.; Richel, A.; Daube, G.; et al. Non Digestible Oligosaccharides Modulate the Gut Microbiota to Control the Development of Leukemia and Associated Cachexia in Mice. PloS One2015, 10, e0131009.

141. Shashkova, T.; Popenko, A.; Tyakht, A.; Peskov, K.; Kosinsky, Y.; Bogolubsky, L.; Raigorodskii, A.; Ischenko, D.; Alexeev, D.; Govorun, V. Agent Based Modeling of Human Gut Microbiome Interactions and Perturbations. PloS One2016, 11, e0148386.

142. Bron, P.A.; Kleerebezem, M.; Brummer, R.-J.; Cani, P.D.; Mercenier, A.; MacDonald, T.T.; Garcia-Ródenas, C.L.; Wells, J.M. Can probiotics modulate human disease by impacting intestinal barrier function? Br. J. Nutr.2017, 117, 93-107.

143. García-Peris, P.; Velasco, C.; Lozano, M.A.; Moreno, Y.; Paron, L.; de la Cuerda, C.; Bretón, I.; Camblor, M.; García-Hernández, J.; Guarner, F.; et al. Effect of a mixture of inulin and fructo-oligosaccharide on Lactobacillus and Bifidobacterium intestinal microbiota of patients receiving radiotherapy: a randomised, double-blind, placebocontrolled trial. Nutr. Hosp.2012, 27, 1908-1915.

144. Catinean, A.; Neag, M.A.; Muntean, D.M.; Bocsan, I.C.; Buzoianu, A.D. An overview on the interplay between nutraceuticals and gut microbiota. PeerJ2018, 6, e4465. 
145. Iranshahi, M.; Rezaee, R.; Parhiz, H.; Roohbakhsh, A.; Soltani, F. Protective effects of flavonoids against microbes and toxins: The cases of hesperidin and hesperetin. Life Sci.2015, 137, 125-132.

146. Chaiyasut, C.; Pengkumsri, N.; Sirilun, S.; Peerajan, S.; Khongtan, S.; Sivamaruthi, B.S. Assessment of changes in the content of anthocyanins, phenolic acids, and antioxidant property of Saccharomyces cerevisiae mediated fermented black rice bran. $A M B$ Express2017, 7, 114.

147. Li, Y.; Yao, J.; Han, C.; Yang, J.; Chaudhry, M.T.; Wang, S.; Liu, H.; Yin, Y. Quercetin, Inflammation and Immunity. Nutrients2016, 8, 167.

148. Larrosa, M.; Yañéz-Gascón, M.J.; Selma, M.V.; González-Sarrías, A.; Toti, S.; Cerón, J.J.; Tomás-Barberán, F.; Dolara, P.; Espín, J.C. Effect of a low dose of dietary resveratrol on colon microbiota, inflammation and tissue damage in a DSS-induced colitis rat model. J. Agric. Food Chem.2009, 57, 2211-2220.

149. Fournomiti, M.; Kimbaris, A.; Mantzourani, I.; Plessas, S.; Theodoridou, I.; Papaemmanouil, V.; Kapsiotis, I.; Panopoulou, M.; Stavropoulou, E.; Bezirtzoglou, E.E.; et al. Antimicrobial activity of essential oils of cultivated oregano (Origanum vulgare), sage (Salvia officinalis), and thyme (Thymus vulgaris) against clinical isolates of Escherichia coli, Klebsiella oxytoca, and Klebsiella pneumoniae. Microb. Ecol. Health Dis.2015, 26, 23289. 


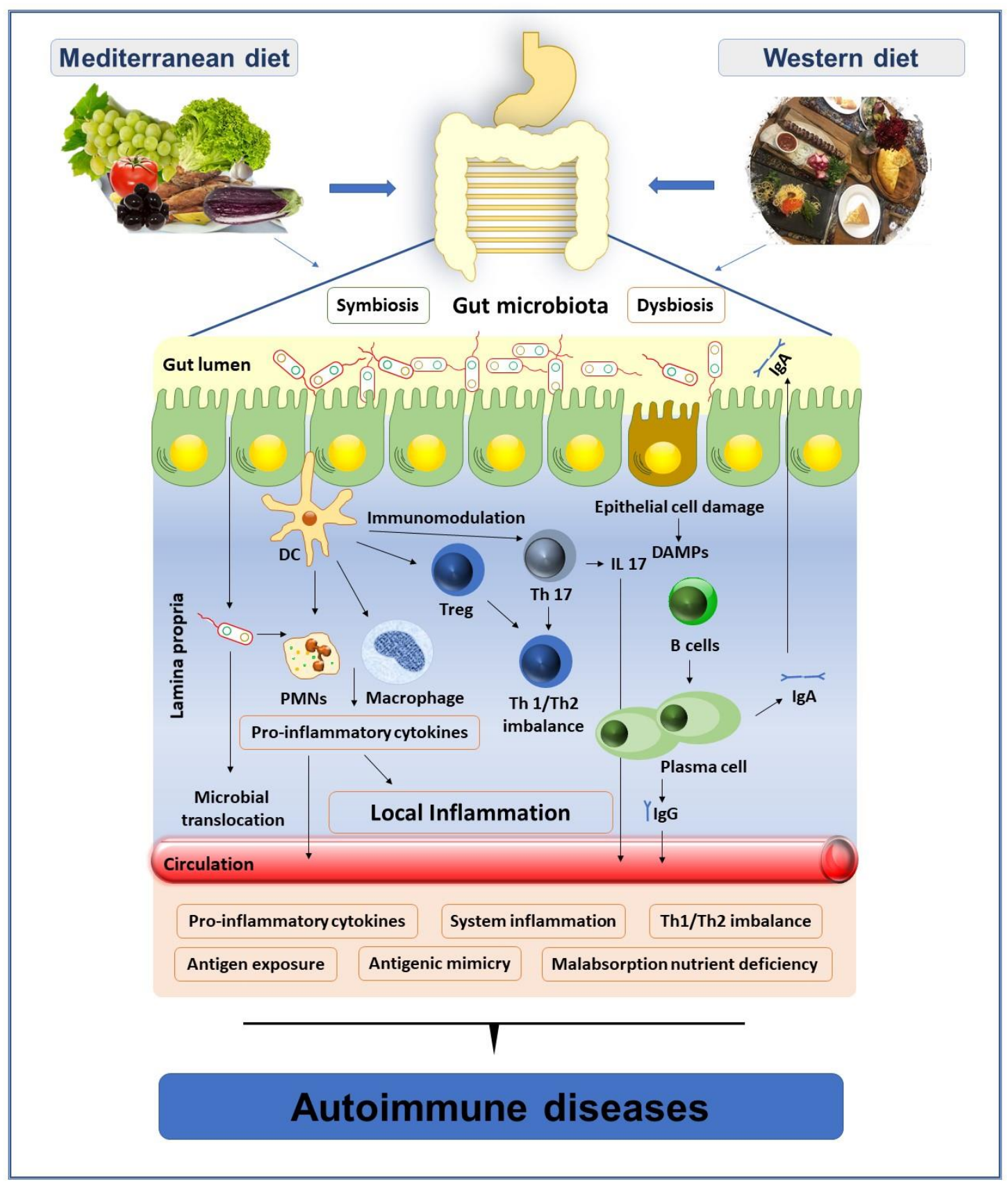

\section{Figure 1}

The nutritional habits regulate the gut microbiota and may provoke or prevent autoimmunity. The Med Diet activate gut microbial symbiosis, on the other hand Western diet seems to be a critical player for microbial dysbiosis and that may develop Autoimmune diseases. The human gut microbiota plays a key role in the intestinal homeostasis and shapes the immune response. The interaction between immune cells and different microbial PAMPs - (Pathogens Associated Molecular Patterns)such as LPS or bacterial DNA activates Dendritic cells (DC), which may elicit the T cells polarization towards Th17, Th1, and Treg subsets. The Th17 cells act against pathogens 
and promote the emergence of autoimmunity. Moreover, bacterial translocation lead to phagocyte cells activation, production of pro-inflammatory cytokines such as IL-1b, and in an upregulation of local inflammation, epithelial cells damage and DAMPs (Damage-Associated Molecular Patterns) formation which activate the B cells for antibody production. 